\title{
Influence of Calcium Acetate Concentration in Electrolyte on Tribocorrosion Behaviour of MAO Treated Titanium
}

\author{
Luís Sousa 1,2,*, Ana Rita Mendes ${ }^{1}$, Ana Maria Pires Pinto 1,3, Fatih Toptan 1,4,5,*价 and Alexandra Cruz Alves 1,5 \\ 1 CMEMS-UMinho-Center of MicroElectroMechanical Systems, Campus de Azurém, Universidade do Minho, \\ 4800-058 Guimarães, Portugal; a85605@alunos.uminho.pt (A.R.M.); anapinto@dem.uminho.pt (A.M.P.P.); \\ alexandra@dem.uminho.pt (A.C.A.) \\ 2 DEMM-Department of Metallurgical and Materials Engineering, Faculdade de Engenharia, \\ Universidade do Porto, 4200-455 Porto, Portugal \\ 3 DEM-Department of Mechanical Engineering, Campus de Azurém, Universidade do Minho, \\ 4800-058 Guimarães, Portugal \\ 4 Department of Materials Science and Engineering, Izmir Institute of Technology, Izmir 35430, Turkey \\ 5 Department of Mechanical Engineering, IBTN/Euro-European Branch of the Institute of Biomaterials, \\ Tribocorrosion and Nanomedicine, Universidade do Minho, 4800-058 Guimarães, Portugal \\ * Correspondence: a65256@alunos.uminho.pt (L.S.); fatihtoptan@iyte.edu.tr (F.T.)
}

Citation: Sousa, L.; Mendes, A.R.; Pinto, A.M.P.; Toptan, F.; Alves, A.C. Influence of Calcium Acetate Concentration in Electrolyte on Tribocorrosion Behaviour of MAO Treated Titanium. Metals 2021, 11, 1985. https://doi.org/10.3390/ met11121985

Academic Editor: Sebastian Feliú, Jr.

Received: 29 October 2021

Accepted: 6 December 2021

Published: 9 December 2021

Publisher's Note: MDPI stays neutral with regard to jurisdictional claims in published maps and institutional affiliations.

Copyright: (c) 2021 by the authors. Licensee MDPI, Basel, Switzerland. This article is an open access article distributed under the terms and conditions of the Creative Commons Attribution (CC BY) license (https:/ / creativecommons.org/licenses/by/ $4.0 /)$.

\begin{abstract}
Ti-based materials are widely used for dental and orthopaedic implant applications due to their adequate mechanical properties, corrosion behaviour and biocompatibility. However, these materials are biologically inert and display poor wear resistance. In one of the most studied processes that aims to overcome these drawbacks, Ti surfaces are often covered by anodic oxide films with the incorporation of bioactive agents such as $\mathrm{Ca}$ and $\mathrm{P}$. Although there are several works on the tribocorrosion behaviour of MAO-treated Ti surfaces, the influence of electrolyte composition on the corrosion kinetics under sliding is yet to be fully understood. In the present work, anodic oxide films were produced on $\mathrm{cp}$-Ti surfaces with different calcium acetate concentrations in the electrolyte. Tribocorrosion behaviour was investigated by reciprocating sliding tests performed in 8 $\mathrm{g} / \mathrm{L} \mathrm{NaCl}$ solution at body temperature, under potentiostatic conditions. The results showed that higher concentrations of calcium acetate had a detrimental effect on tribocorrosion kinetics, however, they resulted in less mechanical damage due to alterations in the topography and structure of the MAO layer.
\end{abstract}

Keywords: titanium; micro-arc oxidation; tribocorrosion

\section{Introduction}

$\mathrm{Ti}$ and Ti alloys are widely used in dental and orthopaedic implants due to their adequate mechanical properties, high corrosion resistance and biocompatibility [1,2]. However, low tribocorrosion resistance is a considerable drawback once these implants are subjected to the cyclical mechanical solicitations present in a corrosive environment such as the human body [3]. Bio-inertness is also a drawback as the implant must possess adequate bioactivity to osseointegrate with the adjacent bone in cementless implants.

Tribocorrosion resistance and bioactivity can be improved trough surface modification and/or surface coatings [3-7]. Among the techniques that can be used, micro-arc oxidation (MAO) or plasma electrolytic oxidation (PEO) is one of the most well-known. In this process, several hundreds of volts are applied to a Ti substrate (immersed in an electrolyte) to promote the dielectric breakdown of a native passive film, and micro-arc discharges, which result in the formation of a thick and micro-porous oxide layer [8-11]. Bioactive and/or antimicrobial species such as $\mathrm{Ca}, \mathrm{P}, \mathrm{Mg}, \mathrm{Si}$, and $\mathrm{Ag}$ can also easily be incorporated into the oxide layer composition by using electrolytes rich in these elements. By controlling the process parameters, mainly electrolyte composition, applied voltage or current, and 
treatment time, it is possible to tailor the MAO layers in terms of thickness, topography, and chemical composition [12].

Over the years, many studies have reported on the corrosive and biological behaviours of these layers with promising results. Regarding corrosion behaviour, studies show that oxide layers obtained by MAO confer about a one to two decade decrease in corrosion kinetics compared to their Ti or Ti alloy base materials, together with a substantial increase in corrosion potential [7,13-16]. On the other hand, biological behaviour studies have shown that MAO layers can have improved cell adhesion, proliferation, and differentiation, as well as antimicrobial properties $[4,6,7,17-21]$. Several reports are also available on the tribocorrosion behaviour; however, most of them only report on the evolution of open circuit potential under sliding action, without considering the corrosion kinetics, whereas very little is known about the evolution of kinetics during mechanical action [22,23]. Marques et al. [22] performed MAO treatment on Ti using different conditions for electrolyte composition and treatment time. The results showed that the overall tribocorrosion resistance can effectively be controlled by optimizing the surface chemistry (by the incorporation of $\mathrm{Ca}$ and $\mathrm{P}$ species), together with the rutile to anatase ratio by selecting the correct MAO treatment parameters. MAO layers with higher amounts of the rutile phase showed lower corrosion rates and reduced material loss due to corrosive mechanisms. On the other hand, Sukuroglu et al. [23] aimed to define suitable MAO treatment parameters to improve the tribocorrosion behavior of Ti. The authors reported that MAO layers with smaller pores and a lower roughness led to the presence of lower currents during mechanical action, corresponding to the higher corrosion resistance under sliding.

It is known that Ca content in the MAO electrolyte changes the nature of the formed oxide films [16,24]. However, its influence on the tribo-electrochemical behaviour of the MAO layers is yet to be understood. Thus, the main objective of this work was to compare the evolution of corrosion kinetics under sliding on MAO-treated surfaces formed in electrolytes with different calcium acetate concentrations.

\section{Materials and Methods}

\subsection{MAO Treatment}

Before MAO treatments, cp-Ti grade 2 (Goodfellow) plates with dimensions of $20 \mathrm{~mm} \times 20 \mathrm{~mm} \times 2 \mathrm{~mm}$ were grounded down to 600 mesh using SiC papers, followed by acid washing in Kroll's reagent $\left(\mathrm{V}_{\mathrm{HF}}: \mathrm{oV}_{\mathrm{HNO} 3}: \mathrm{V}_{\mathrm{H} 2 \mathrm{O}}=1: 1: 1\right)$ for $10 \mathrm{~s}$. Afterwards, the samples were ultrasonically cleaned in propanol and distilled water for 10 and 5 min, respectively.

MAO treatments were performed in an electrochemical cell containing $200 \mathrm{~mL}$ of electrolyte, composed of a mixture of $\beta$-glycerophosphate disodium salt pentahydrate ( $\beta$ - GP-Alfa Aesar), and different concentrations of calcium acetate monohydrate (CA-Alfa Aesar), as shown in Table 1. The Ti plates (exposed area of $9.6 \mathrm{~cm}^{2}$ ) were connected as anodes, while a Pt sheet $\left(5.94 \mathrm{~cm}^{2}\right)$ distanced $8 \mathrm{~cm}$ from the Ti plate was connected as the cathode. All the treatments were performed in a DC power supply (Agilent technologies $\mathrm{N} 5772 \mathrm{~A})$ in potentiostatic mode $(300 \mathrm{~V})$ for $1 \mathrm{~min}$, under a turbulent regime produced by means of a magnetic stirrer spinning at $200 \mathrm{rpm}$.

Table 1. Groups and respective electrolyte composition.

\begin{tabular}{cc}
\hline Group & Electrolyte \\
\hline cp-Ti (control) & Just etched \\
015CA & $0.02 \mathrm{M} \beta-\mathrm{GP}+0.15 \mathrm{M} \mathrm{CA}$ \\
035CA & $0.02 \mathrm{M} \beta-\mathrm{GP}+0.35 \mathrm{M} \mathrm{CA}$ \\
\hline
\end{tabular}

\subsection{Tribocorrosion Tests}

For tribocorrosion tests, samples were first placed in a tribo-electrochemical cell containing $30 \mathrm{~mL}$ of $\mathrm{NaCl}$ solution $(8 \mathrm{~g} / \mathrm{L})$ at body temperature $\left(37 \pm 2{ }^{\circ} \mathrm{C}\right)$. The cell was 
then mounted in a tribometer (CETR-UMT-2, Bruker, Massachusetts, MA, USA) with a linear reciprocating motion ball-on-plate configuration, where an alumina ball (Ceratec) with a $10 \mathrm{~mm}$ diameter was used as a counter-body. Before sliding, OCP values were monitored until stabilization. After that, the last measured value of potential was applied, and the evolution of current was measured. Once the current reached stable values, sliding was started. All the tests were performed under $1.5 \mathrm{~N}$ load (corresponding to a maximum Hertzian contact pressure of $494 \mathrm{MPa}$, and mean Hertzian contact pressure of $330 \mathrm{MPa}$ for cp-Ti), $1 \mathrm{~Hz}$ sliding frequency, $3 \mathrm{~mm}$ of total amplitude, and $30 \mathrm{~min}$ sliding time. All electrochemical tests were performed using a potentiostat/galvanostat (Reference 600, Gamry Instruments, Pennsylvania, PA, USA). At least 3 tests were performed per condition in order to assure the repeatability of results, and after each test the samples were rinsed with distilled water.

\subsection{Characterization}

Topography, microstructure, and the overall chemical composition of MAO-treated groups before and after tribocorrosion tests were evaluated using a field emission gun scanning electron microscope (FEG-SEM-FEI NOVA 200, Thermo Fisher, Waltham, MA, USA), and energy dispersive X-Ray spectroscopy (Pegasus X4M, EDAX, Mahwah, NJ, USA). Cross-sectional optical microscope (DM2500, Leica, Wetzlar, Germany) images of MAO layers were obtained by embedding the samples in resin, then cutting and grinding (until $2400 \mathrm{mesh}$ ), and finally mirror-finishing with colloidal silica $(0.2 \mu \mathrm{m})$. Alternatively, the cross-sections of the anodic oxide films were prepared by nano-machining using the focused ion beam of a SEM-FIB (Nova 600 NanoLab, Thermo Fisher, Waltham, MA, USA), and characterized by FEG-SEM/EDS. Surface roughness and wear profiles were obtained by profilometry (Dektak 150, Veeco, New York, NY, USA).

\section{Results and Discussion}

\subsection{MAO-Treated Surfaces}

The overall microstructure of Ti before and after MAO treatments can be seen in Figure $1 \mathrm{a}-\mathrm{c}$. In the case of untreated $\mathrm{Ti}$ surfaces, it is possible to observe the typical granular structure of Ti. On the other hand, after MAO treatment both surfaces revealed the typical volcano-like structure, characterized by the formation of a multi-scale porous structure.
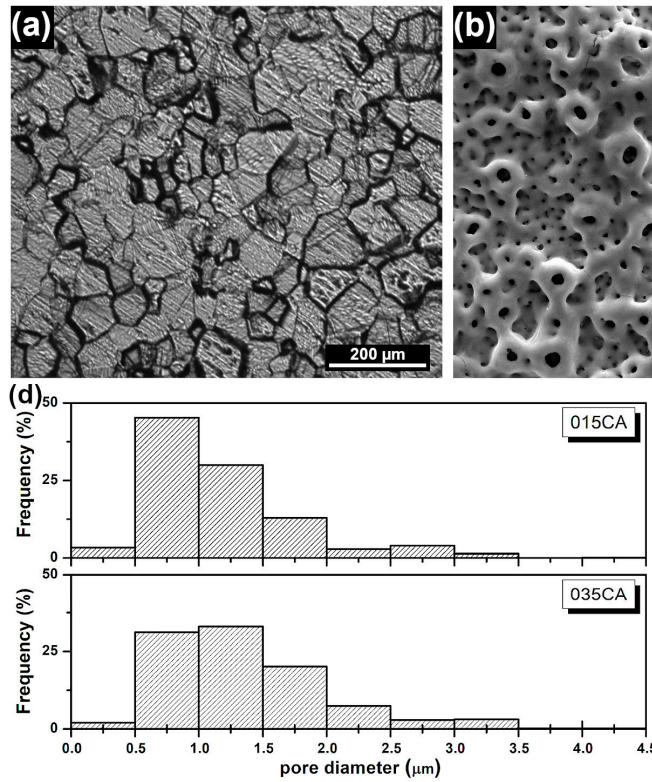
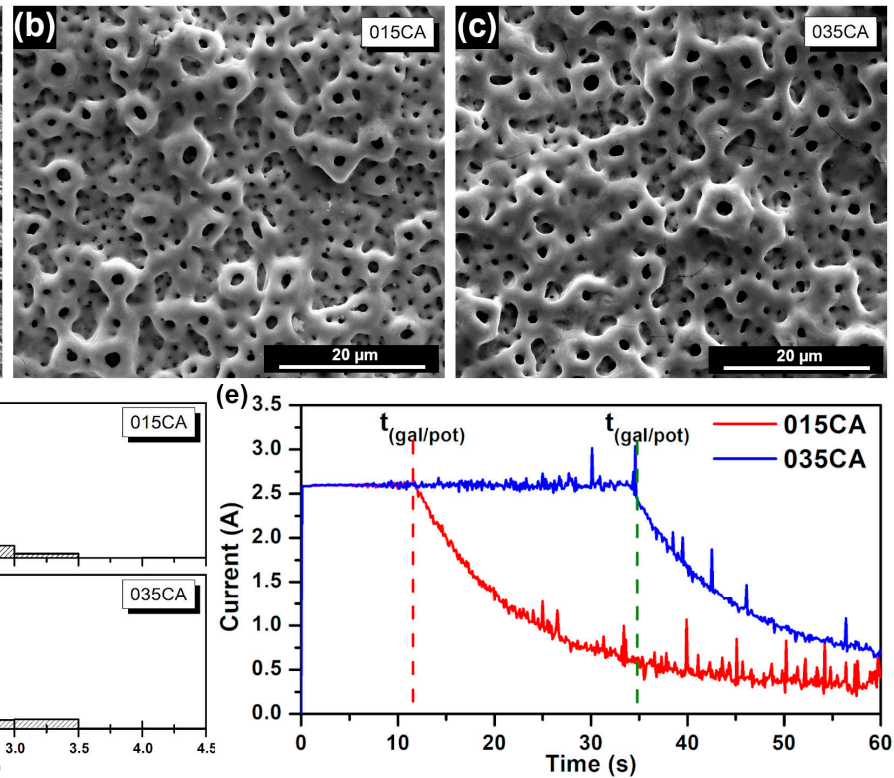

Figure 1. (a) Optical microscope image of Ti after etching; $(\mathbf{b}, \mathbf{c})$ SE SEM images of Ti after MAO treatments; (d) pore size distribution for MAO groups; (e) evolution of current during MAO treatments. 
Pore size distribution (Figure 1d) was assessed by a point-counting method based on ASTM E562, and the methodology is described elsewhere [16]. On average, the 015CA group contained smaller pores, mostly in the $0.5-1 \mu \mathrm{m}$ range, while the 035CA group contained a larger pore size distribution, ranging from 0.5 to $1.5 \mu \mathrm{m}$. An increase in pore size due to an increase in calcium acetate concentration in the electrolyte has been reported. By changing the electrolyte concentration, the dielectric breakdown that occurs during the MAO treatment changes, and thus the pore size is different. On the other hand, by increasing the calcium acetate concentration, the conductivity of the electrolyte increases; this is the main reason for the enlargement of pore size [16,25-27].

Figure 1e presents the evolution of current during the MAO treatments, which can be divided into two distinct zones, i.e., the galvanostatic and potentiostatic zones. The first zone (galvanostatic) is characterized by a constant current of $2.6 \mathrm{~A}$ (the current-limit of the power supply), which lasted until $300 \mathrm{~V}$ was reached. During the first stage, the high current values led to a fast growth in the oxide film, together with an increase in micro-arcs occurring at the surface. As soon as $300 \mathrm{~V}$ was reached, a decrease in the current was observed, where micro-arc discharges led to current oscillations [1,16]. These microarc discharges are known to cause localised melting and the formation of micro-pores. Moreover, once the oxide layer reaches a critical thickness, the applied voltage leads to the electrical breakdown of these layers and micro-arc discharges (the current peaks in the potentiostatic zone). Consequently, these discharges lead to localized melting, and the formation of micro-pores, and thus formation of the volcano-like structure. As the treatment time increases, the number of micro-arcs is reduced; however, they can be more energetic, which leads to the appearance of larger pores.

Table 2 presents the tgal/pot times and the electric charge (Q) obtained from integrating the graphs for both MAO groups. On average, the 035CA group took around three times longer to pass into the potentiostatic zone, and presented almost double the electric charge compared to the 015CA group. These values may explain the increased thickness of the MAO layers obtained. Chemical analysis revealed the incorporation of $\mathrm{Ca}$ and $\mathrm{P}$ elements from the electrolyte, where the 015CA group presented a $\mathrm{Ca} / \mathrm{P}$ ratio of $1.61 \pm 0.09$, whereas values for the $035 \mathrm{CA}$ group were $2.73 \pm 0.11(\%)$. In a previous work of the last author, it was also reported that the MAO layers for a 015CA group produced under identical conditions were composed of $100 \%$ anatase, while a mixture of $70 \%$ anatase and $30 \%$ rutile was obtained for the 035CA group [16]. On the other hand, Oliveira et al. [1] treated Ti by MAO with similar conditions for the 035CA group. The authors used coupled AFM-Raman and TEM analyses to characterize the MAO surfaces; the results showed that while anatase was distributed in all treated surfaces, the rutile phase was preferentially located on the top of the volcano-like structures. Moreover, TEM results showed that the inner part of the oxide was a mixture of crystalline and amorphous material, whereas the top of the oxide was covered by an amorphous region. Moreover, while small nanocrystals of rutile were observed near the top region of the oxide, the anatase phase was mainly found in the bottom part of the MAO layer.

Table 2. $\mathrm{T}_{\text {gal/pot }}$ and electric charge $(\mathrm{Q})$ for MAO-treated groups.

\begin{tabular}{ccc}
\hline Group & $\mathbf{T}_{\text {gal } / \text { pot }}(\mathbf{s})$ & $\mathbf{Q}(\mathbf{C})$ \\
\hline 015CA & $8.68 \pm 3.84$ & $67.31 \pm 14.33$ \\
035CA & $31.24 \pm 5.55$ & $120.23 \pm 4.49$ \\
\hline
\end{tabular}

Figure 2 presents OM and SEM images of the cross-sections of both MAO layers. It is possible to observe, on the OM images (Figure 2a,b), an increased thickness with increased calcium acetate concentration. The thickness of the anodic films was measured by image analysis. The 035CA group had a slightly increased thickness of $6.31 \pm 1.29 \mu \mathrm{m}$ compared to the 015CA group $(3.83 \pm 0.65 \mu \mathrm{m})$. As can be observed in Table 2, as the concentration of calcium acetate increased, both tgal/pot and $Q$ values also increased, which might explain the differences in MAO layer thickness. Wu et al. [25] stated that increasing the 
calcium acetate concentration in the MAO electrolyte improved the electrical conductivity, affecting the breakdown potential of the oxide layer. It is also known that increasing the calcium acetate concentration leads to an increased MAO surface roughness $[16,28]$. Alves et al. [16] showed that after the MAO treatment, the roughness increased around four times compared to an etched cp-Ti surface among the MAO-treated groups. Thus, increasing the $\mathrm{CA}$ concentration led to a thicker MAO layer, rougher surface, and bigger pore size. Both the 015CA and 035CA group MAO layers presented three distinct layers (Figure 2c,d). Just after the bulk Ti had grown, a thin and compact oxide layer was formed, followed by two different porous layers. The inner porous layer is characterized by pores of smaller dimensions, while the outer porous layer contains bigger pores. These results are in accordance with the literature for MAO-treated Ti produced under identical conditions $[16,29]$.

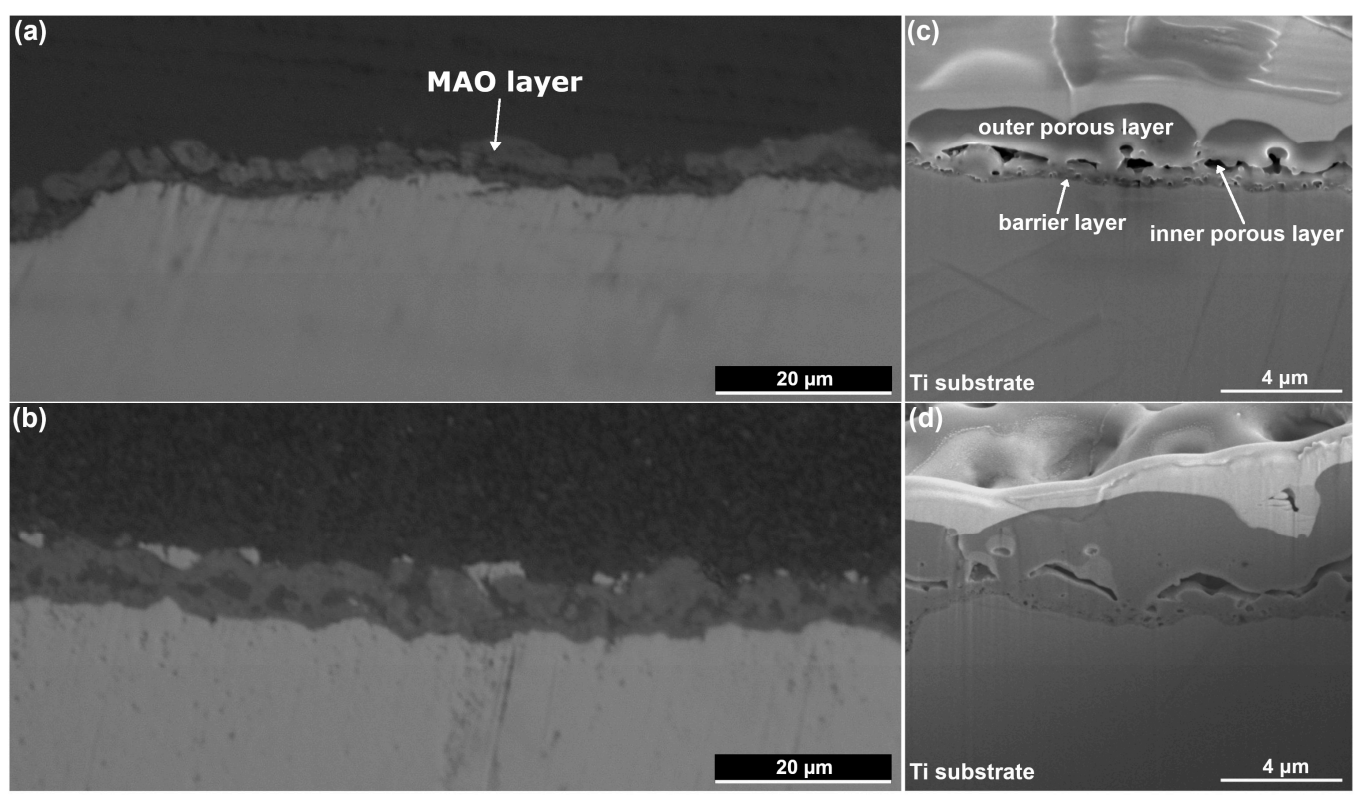

Figure 2. Cross-sectional OM, and FIB prepared cross-sectional SE/SEM images of $(\mathbf{a}, \mathbf{c})$ 015CA and (b,d) 035CA samples, respectively.

\subsection{Tribocorrosion Behavior}

\subsubsection{Tribo-Electrochemical Measurements}

The evolution of current density before, during, and after sliding, and the evolution of COF during sliding are presented in Figure 3. Before sliding, all the groups presented stable current density values due to the formation of a stable passive oxide film in the case of $\mathrm{Ti}$, and due to the high corrosion resistance of MAO layers in the MAO groups. A significant decrease in current density was observed for both MAO-treated groups when compared with untreated Ti. However, slight increase in current density values was observed from the $015 \mathrm{CA}$ to $035 \mathrm{CA}$ groups that may be explained by the higher average pore size. The average current density values before sliding were approximately $3.9 \mu \mathrm{A} \mathrm{cm}^{-2}$, $0.1 \mu \mathrm{A} \mathrm{cm}^{-2}$, and $0.3 \mu \mathrm{A} \mathrm{cm}{ }^{-2}$ for the $\mathrm{Ti}, 015 \mathrm{CA}$, and 035CA groups, respectively, due to the higher corrosion resistance of the MAO layers. Several works have shown that MAO layers possess higher corrosion potentials, and significantly lower current densities in the passive domain when compared with untreated titanium $[1,9,15,16,27]$. In a previous work [16], although an improved corrosion resistance was observed on MAOtreated $\mathrm{Ti}$, higher concentrations of calcium acetate resulted in a negative effect on the corrosion behaviour. The authors explained this behaviour with the increased crack density present in the outermost porous layer, together with the increased pore size. These properties can facilitate electrolyte penetration through the MAO layer, thus affecting its corrosion resistance. 

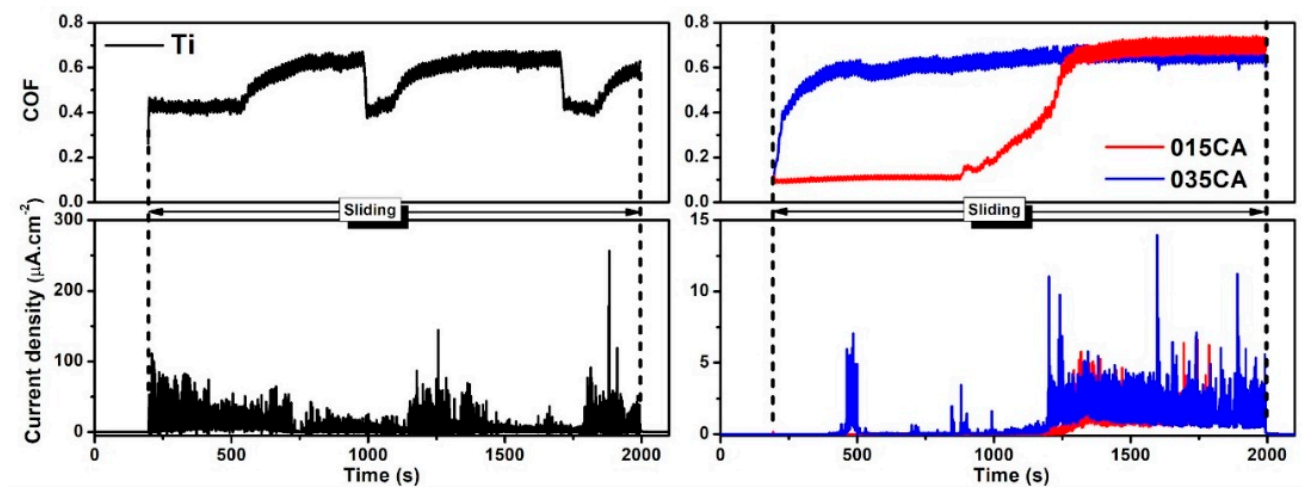

Figure 3. Evolution of current density before, during and after sliding, alongside the evolution of COF during sliding.

As soon as sliding started, values of current density in Ti demonstrated the typical sharp increase that is attributed to the removal of the passive film, and the exposure of fresh metallic area to the electrolyte. During sliding, increases and decreases were observed in both current density and COF values. This behaviour can be explained by the formation/breakdown of tribolayers during sliding. The wear debris formed during sliding action can be compacted on the worn surface and lead to the formation of tribolayers, which offer limited protection against corrosion, and thus a decrease in current density was observed. Eventually, tribolayers can be broken, thus, a consequent increase in current density values was observed. This process can be repeated several times during sliding. Since these tribolayers have different properties to the base material, and influence the overall topography of the worn surfaces, alterations in COF values are also usually observed [15].

The MAO groups demonstrated considerably different behaviour, no significant changes were observed in current density values from the onset of sliding. In fact, only after around $15 \mathrm{~min}$ of sliding for both groups was a small increase in current density values observed. Nonetheless, current density values were still much lower than those observed in Ti. Table 3 presents the electrical charge $(\mathrm{Q})$ transfer between the worn surface and the electrolyte, obtained by integrating the curves, using the starting current as a baseline. $Q$ values were more than ten times lower for both MAO groups, with no clear differences between them. These values suggest much lower corrosion kinetics on the wear tracks of MAO groups. Marques et al. [22] studied the influence of different electrolyte compositions and MAO treatment times on the tribocorrosion behaviour of Ti. The authors noticed that MAO-treated Ti with lower calcium acetate concentrations presented a gradual increase in current values, and after some sliding time the current values reached values close to those seen in untreated Ti. However, for higher concentrations of calcium acetate, no significant variation in current density values was observed for the first few minutes of sliding. After that, a slight increase in current values was noticed; however, they never reached the current values of untreated Ti. The authors attributed this behaviour to the surface characteristics of the MAO layers, alongside the thickness, and hardness of the rutile phase present.

Comparing the evolution of $\mathrm{COF}$ in the $\mathrm{MAO}$ layers, the 015CA group presented very low COF values for the first few minutes of sliding, whereas, afterwards, a drastic increase and subsequent stabilization in COF was observed. On the other hand, COF values for the 035CA group increased rapidly from the onset of sliding, and after some time COF values stabilized, presenting a relatively horizontal course from then until the end of sliding. The results suggest that the overall properties of the MAO layers play a significant role in their overall tribological behaviour. It has been reported that elemental $P$ has a lubricant effect in $\mathrm{TiO}_{2}$ layers obtained by anodic treatment [30]. Thus, the lower COF values observed for the 015CA group may be related to the higher contribution of $\mathrm{P}$ due to the lower $\mathrm{Ca} / \mathrm{P}$ ratio. 
Lower corrosion kinetics have been reported in the literature both without [16] and with [23] sliding, due to the smaller pores and lower number of cracks in MAO layers formed on cp-Ti. On the other hand, Sukuroglu et al. [23] also reported that COF was affected by the morphology of MAO layers, where low surface roughness, and smaller pores in the surface resulted in lower values of COF. Therefore, the difference between the MAO groups observed during approximately the first half of sliding may be attributed to differences in the topography of the MAO layers. Afterwards, when the outer MAO layer was damaged, the behavior of the MAO groups was very similar in terms of both current density and COF evolution.

Table 3. Electric charge (Q) transfer between the worn surfaces and electrolyte.

\begin{tabular}{cc}
\hline Group & $\mathbf{Q}(\mathbf{m C})$ \\
\hline Ti & $12.10 \pm 1.00$ \\
015CA & $0.61 \pm 0.40$ \\
035CA & $1.19 \pm 0.55$ \\
\hline
\end{tabular}

\subsubsection{Characterization of the Worn Surfaces}

Representative optical microscope images and wear-track profiles of the worn surfaces for all the groups are presented in Figure 4. Overall, MAO groups presented much less weardamage compared to Ti. Under magnification, it seems that the 035CA group presented less wear-damage compared to the 015CA group. The average wear-track width decreased from $350 \pm 32 \mu \mathrm{m}$ to $299 \pm 25 \mu \mathrm{m}$ for the 015CA and 035CA groups, respectively. However, once the extent of wear-damage was within the range of pore size, the calculation of wearvolume was not reliable enough to distinguish between the two groups. Nonetheless, the reduced wear-damage for the 035CA group, revealed by the reduced wear track width and depth, may be related to the increased thickness of the MAO layer, as well as the presence of rutile, which is harder and thus more wear-resistant than anatase [31].
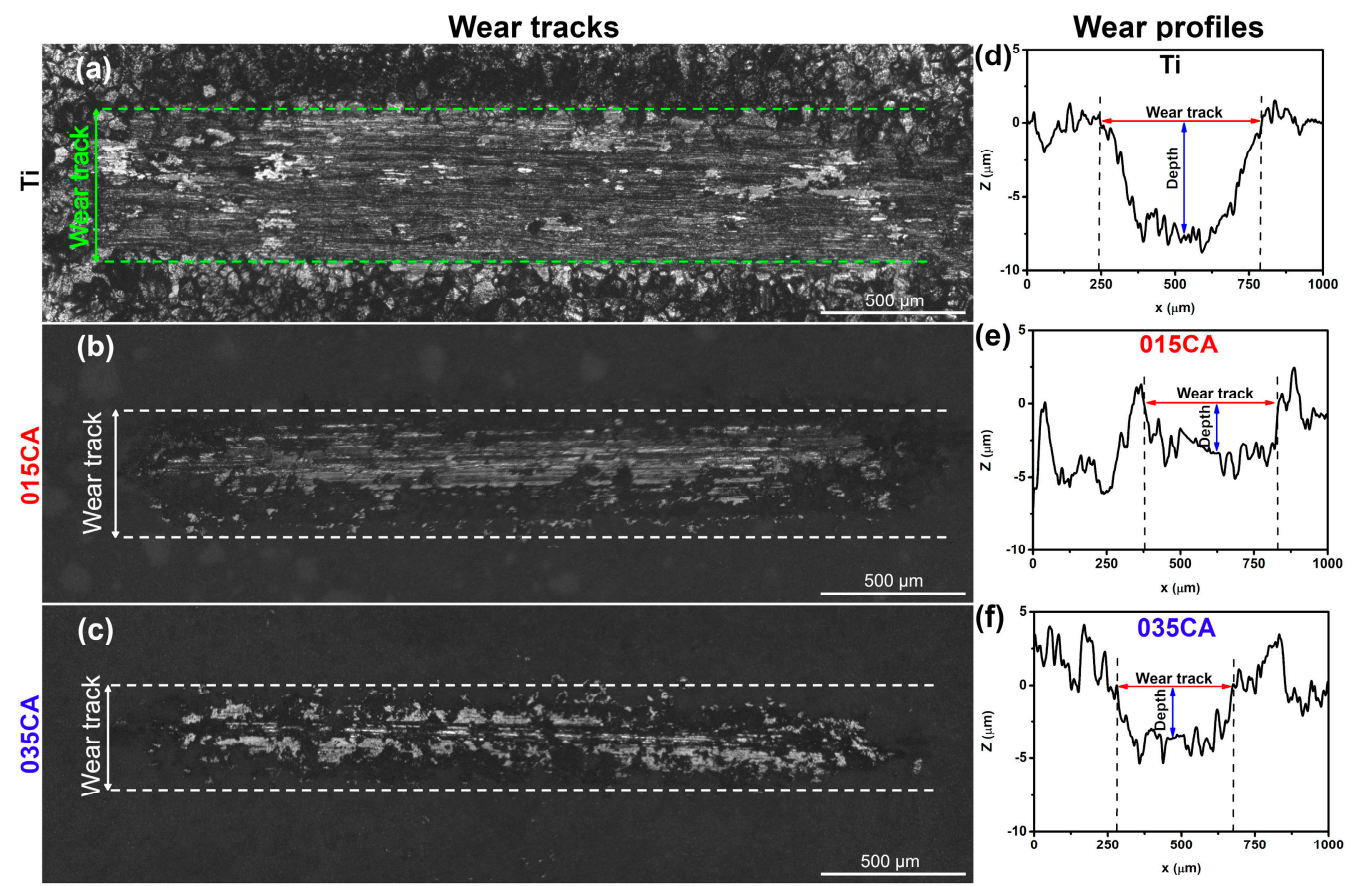

Figure 4. Optical microscope images of the worn surfaces for (a) Ti, (b) 015CA and (c) 035CA and wear-track profiles of the worn surfaces for (d) Ti, (e) 015CA and (f) $035 \mathrm{CA}$. 
An SEM/EDS analysis of the worn sample and counter-body surfaces is presented in Figure 5. The worn surfaces of Ti (Figure 5a) were mainly composed of ploughing grooves, due to a combination of adhesive and abrasive wear mechanisms, and the presence of compacted, oxidized, wear-debris. Due to the high reactivity of Ti, material is removed from the worn surface by the counter-body due to adhesion. Consequently, this wear debris can be adhered to the counter-body (Figure 5h), compacted on the wear track (Z1 in Figure 5a), or ejected. The adherence of material onto the counter-body results in the formation of ploughing grooves. On the other hand, the compacted wear debris (tribolayer) provides limited protection against tribocorrosion, as it protects the substrate material from the electrolyte. Consequently, a decrease in corrosion kinetics is observed. However, the formation and growth of tribolayers results in an increased roughness and, thus, an increase in COF values (Figure 3). Due to repeated material transfer between the mating surfaces, wear debris also tends to oxidize (Figure 5d) and increase its hardness. These mechanisms are typically observed for Ti surfaces tested under similar conditions $[14,15,32]$.
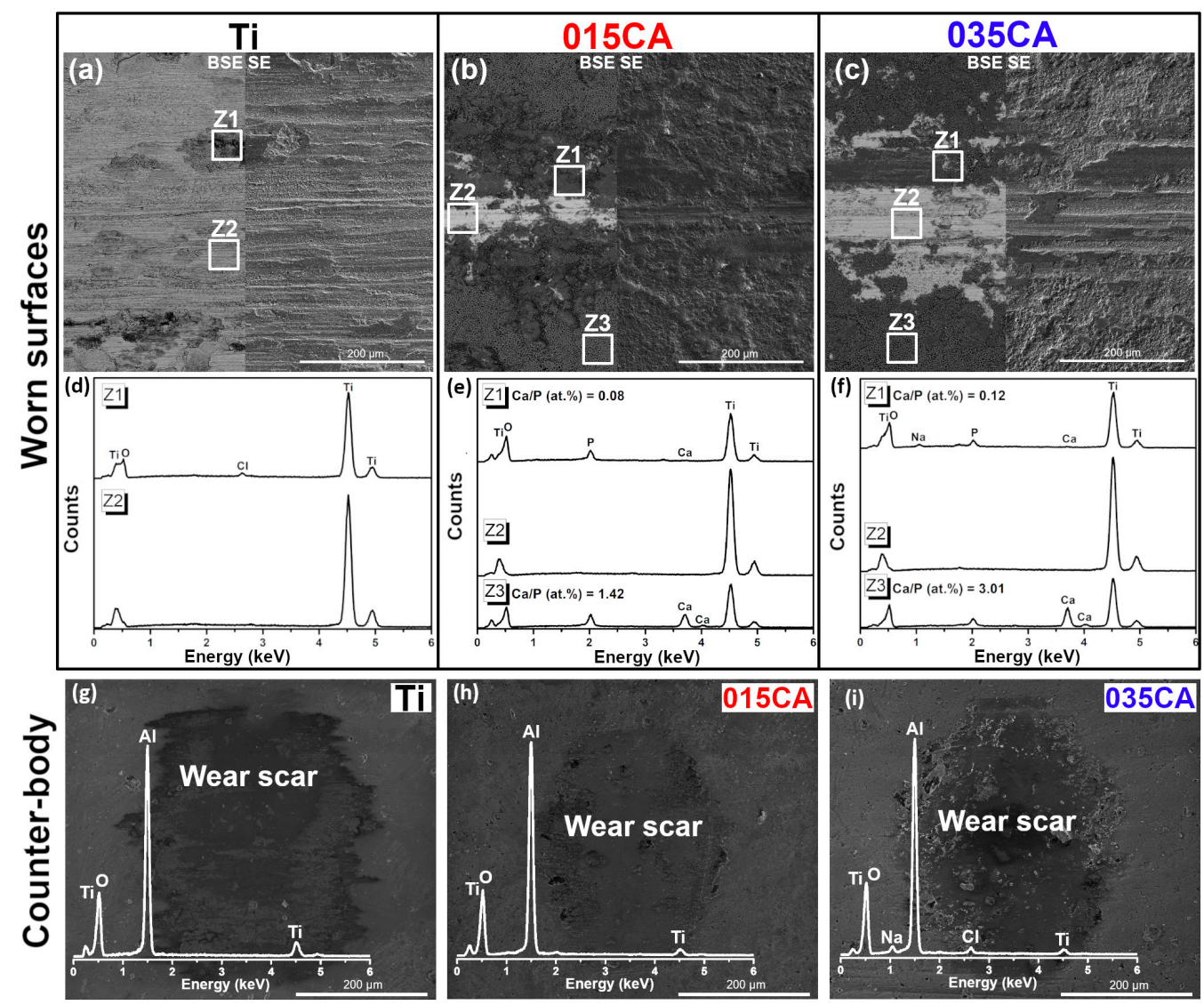

Figure 5. BSE/SE SEM images of the worn surfaces for (a) Ti, (b) 015CA, and (c) 035CA groups, EDS analysis of the worn surfaces for (d) Ti, (e) 015CA and (f) 035CA groups, and SE SEM images and EDS analysis of the counter-body surfaces for (g) Ti, (h) 015CA and (i) 035CA groups.

For MAO-treated groups, it was observed that the outer porous MAO layers were almost completely removed in the centre of the wear track, where no elemental $\mathrm{Ca}$ or $\mathrm{P}$ from these layers was detected ( $\mathrm{Z} 2$ in Figure $5 b, c)$. The formation of grooves was observed in these zones where the counter-body was sliding against the Ti substrate. Around these zones, damaged MAO layers could be observed, where the porous structure was destroyed with a subsequent decrease in $\mathrm{Ca} / \mathrm{P}$ ratios ( $\mathrm{Z} 1$ in Figure 5e,f) compared to the unaffected zones (Z3). However, the wear-damage was still considerably lower than in $\mathrm{Ti}$, as evidenced by the lower $\mathrm{Q}$ values that were obtained. EDS analysis also revealed the transference of Ti from the worn surfaces to the counter body 
(Figure $5 \mathrm{~h}, \mathrm{i}$ ), and thus the presence of adhesive wear. Nonetheless, this was less significant than in the untreated Ti. Oliveira et al. [1] showed that MAO layers formed on cp-Ti are characterized by a gradient in structure alongside its thickness. The authors showed that there is a transition from a harder and more resistant outer porous layer, mostly constituted by rutile, to a softer and more ductile inner layer, where anatase and an amorphous layer was formed. On the other hand, Marques et al. [22] demonstrated that the tribocorrosion damage might be controlled by optimizing the surface chemistry ( $\mathrm{Ca} / \mathrm{P}$ ratio), and nature of the oxide films (rutile/anatase ratio) through selection of the proper MAO treatment parameters.

Alves et al. [24] studied the tribocorrosion behaviour under OCP for similar MAO layers. The authors concluded that the differing nature of oxides formed during MAO treatment played an important role in their tribocorrosion behaviour, where it was seen that MAO layers containing rutile led to a significant decrease in the mechanical damage observed after sliding. However, before the mechanical action started, a lower corrosion tendency was observed for samples treated with the lowest concentrations of calcium acetate. Nevertheless, corrosion resistance is improved by MAO treatment, independent of calcium acetate concentration, when compared with untreated Ti. However, higher concentrations of calcium acetate result in a detrimental effect to corrosion resistance, essentially due to the contribution of the higher crack densities and pore sizes of the outermost porous layer of MAO-treated surfaces [16]. On the other hand, Oliveira et al. [1] showed that, independent to the MAO treatment conditions, only the outer part of the MAO layer was damaged after sliding. Moreover, the material removed from the outer surface might be smashed and pressed into the pores leading to an accumulation of material, which can easily be worn out. Alves et al. [3] also reported that the differences in both electrochemical and wear mechanisms were correlated with the characteristics of the MAO layers. Even though the 035CA group samples suffered less mechanically induced damage after sliding (most likely due to the presence of rutile in their composition), the topography (characterized by an increased crack density and bigger pore size) had a negative effect on the corrosion kinetics. However, the corrosion resistance of MAO-treated samples before, during and after sliding was always much lower when compared to that of untreated $\mathrm{Ti}$, demonstrating the promising properties of Ti-MAO layers. Thus, it can be concluded that the thickness of MAO layers influences the tribocorrosion behaviour of MAO-treated Ti.

\section{Conclusions}

The influence of calcium acetate in the MAO treatment electrolyte, on the corrosion kinetics and tribocorrosion behaviour of cp-Ti MAO-treated surfaces, was assessed in this study. Within the limitations of this work, it can be concluded that electrolyte composition played a significant role in the final properties of the MAO layers, which have an impact on their overall tribocorrosion behaviour. While all MAO-treated surfaces exhibited reduced tribocorrosion kinetics, and reduced wear damage compared to the untreated Ti. Higher concentrations of calcium acetate had a detrimental effect on tribocorrosion kinetics, leading to a slightly increased current density but, at the same time, less mechanical damage due to the presence of rutile in the MAO layer.

Author Contributions: Conceptualization, L.S., A.M.P.P. and A.C.A.; methodology, L.S., A.R.M., F.T. and A.C.A.; validation, L.S., A.R.M. and A.C.A.; investigation, L.S. and A.R.M.; writing-original draft preparation, L.S.; writing-review and editing, L.S., A.M.P.P., F.T. and A.C.A.; supervision, A.C.A. All authors have read and agreed to the published version of the manuscript.

Funding: This work was supported by Portuguese Foundation for Science and Technology (FCT), Portugal, under UIDB/04436/2020 project. L. Sousa was grateful for the PhD grant through NORTE08-5369-FSE-000051 project.

Institutional Review Board Statement: Not applicable.

Informed Consent Statement: Not applicable. 


\section{Data Availability Statement: Not applicable.}

Acknowledgments: The authors would like to acknowledge Jean-Pierre Celis and Luís A. Rocha for the cross-sectional analysis.

Conflicts of Interest: The authors declare no conflict of interest.

\section{References}

1. Oliveira, F.G.; Ribeiro, A.R.; Perez, G.; Archanjo, B.S.; Gouvea, C.P.; Araújo, J.R.; Campos, A.P.C.; Kuznetsov, A.; Almeida, C.M.; Maru, M.M.; et al. Understanding Growth Mechanisms and Tribocorrosion Behaviour of Porous $\mathrm{TiO}_{2}$ Anodic Films Containing Calcium, Phosphorous and Magnesium. Appl. Surf. Sci. 2015, 341, 1-12. [CrossRef]

2. Li, X.; Xu, H.; Zhao, B.; Jiang, S. Accelerated and enhanced osteointegration of MAO-treated implants: Histological and histomorphometric evaluation in a rabbit model. Int. J. Oral Sci. 2018, 10, 11. [CrossRef]

3. Alves, S.A.; Bayón, R.; Igartua, A.; de Viteri, V.S.; Rocha, L.A. Tribocorrosion behaviour of anodic titanium oxide films produced by plasma electrolytic oxidation for dental implants. Lubr. Sci. 2013, 26, 500-513. [CrossRef]

4. Alves, A.C.; Thibeaux, R.; Toptan, F.; Pinto, A.M.P.; Ponthiaux, P.; David, B. Influence of macroporosity on NIH/3T3 adhesion, proliferation, and osteogenic differentiation of MC3T3-E1 over bio-functionalized highly porous titanium implant material. J. Biomed. Mater. Res. Part B Appl. Biomater. 2018, 107, 73-85. [CrossRef] [PubMed]

5. Toptan, F.; Alves, A.C.; Pinto, A.M.P.; Ponthiaux, P. Tribocorrosion behavior of bio-functionalized highly porous titanium. J. Mech. Behav. Biomed. Mater. 2017, 69, 144-152. [CrossRef]

6. Kazek-Kęsik, A.; Leśniak, K.; Orzechowska, B.U.; Drab, M.; Wiśniewska, A.; Simka, W. Alkali treatment of anodized titanium alloys affects cytocompatibility. Metals 2018, 8, 29. [CrossRef]

7. Garcia-Cabezón, C.; Rodriguez-Mendez, M.L.; Borrás, V.A.; Raquel, B.; Cabello, J.C.R.; Fonseca, A.I.; Martin-Pedrosa, F. Application of plasma electrolytic oxidation coating on powder metallurgy Ti-6Al-4V for dental implants. Metals 2020, $10,1167$. [CrossRef]

8. Qadir, M.; Li, Y.; Munir, K.; Wen, C. Calcium Phosphate-Based Composite Coating by Micro-Arc Oxidation (MAO) for Biomedical Application: A Review. Crit. Rev. Solid State Mater. Sci. 2018, 43, 392-416. [CrossRef]

9. Park, I.S.; Woo, T.G.; Jeon, W.Y.; Park, H.H.; Lee, M.H.; Bae, T.S.; Seol, K.W. Surface characteristics of titanium anodized in the four different types of electrolyte. Electrochim. Acta 2007, 53, 863-870. [CrossRef]

10. Fazel, M.; Salimijazi, H.R.; Golozar, M.A.; Garsivaz jazi, M.R. A comparison of corrosion, tribocorrosion and electrochemical impedance properties of pure Ti and Ti6Al4V alloy treated by micro-arc oxidation process. Appl. Surf. Sci. 2015, 324, 751-756. [CrossRef]

11. Shokouhfar, M.; Dehghanian, C.; Montenero, A.; Baradaran, A. Preparation of ceramic coating on Ti substrate by plasma electrolytic oxidation in different electrolytes and evaluation of its corrosion resistance: Part II. Appl. Surf. Sci. 2012, 258, 2416-2423. [CrossRef]

12. Santos, E.; de Souza, G.B.; Serbena, F.C.; Santos, H.L.; de Lima, G.G.; Szesz, E.M.; Lepienski, C.M.; Kuromoto, N.K. Effect of anodizing time on the mechanical properties of porous titania coatings formed by micro-arc oxidation. Surf. Coat. Technol. 2017, 309, 203-211. [CrossRef]

13. Matykina, E.; Arrabal, R.; Mingo, B.; Mohedano, M.; Pardo, A.; Merino, M.C. In vitro corrosion performance of PEO coated Ti and Ti6Al4V used for dental and orthopaedic implants. Surf. Coat. Technol. 2016, 307, 1255-1264. [CrossRef]

14. Sousa, L.; Basilio, L.; Alves, A.C.; Toptan, F. Tribocorrosion-resistant biofunctionalized Ti- $\mathrm{Al}_{2} \mathrm{O}_{3}$ composites. Surf. Coat. Technol. 2021, 420, 127329. [CrossRef]

15. Costa, A.I.; Sousa, L.; Alves, A.C.; Toptan, F. Tribocorrosion behaviour of bio-functionalized porous Ti surfaces obtained by two-step anodic treatment. Corros. Sci. 2020, 166, 108467. [CrossRef]

16. Alves, A.C.; Wenger, F.; Ponthiaux, P.; Celis, J.-P.; Pinto, A.M.; Rocha, L.A.; Fernandes, J.C.S. Corrosion mechanisms in titanium oxide-based films produced by anodic treatment. Electrochim. Acta 2017, 234, 16-27. [CrossRef]

17. Alves, S.A.; Bayón, R.; de Viteri, V.S.; Garcia, M.P.; Igartua, A.; Fernandes, M.H.; Rocha, L.A. Tribocorrosion Behavior of Calciumand Phosphorous-Enriched Titanium Oxide Films and Study of Osteoblast Interactions for Dental Implants. J. Bio Tribo Corros. 2015, 1, 23. [CrossRef]

18. Ribeiro, A.R.; Oliveira, F.; Boldrini, L.C.; Leite, P.E.; Falagan-Lotsch, P.; Linhares, A.B.R.; Zambuzzi, W.F.; Fragneaud, B.; Campos, A.P.C.; Gouvêa, C.P.; et al. Micro-arc oxidation as a tool to develop multifunctional calcium-rich surfaces for dental implant applications. Mater. Sci. Eng. C 2015, 54, 196-206. [CrossRef]

19. Teker, D.; Muhaffel, F.; Menekse, M.; Karaguler, N.G.; Baydogan, M.; Cimenoglu, H. Characteristics of multi-layer coating formed on commercially pure titanium for biomedical applications. Mater. Sci. Eng. C 2015, 48, 579-585. [CrossRef]

20. Banakh, O.; Snizhko, L.; Journot, T.; Gay, P.A.; Csefalvay, C.; Kalinichenko, O.; Girin, O.; Marger, L.; Durual, S. The influence of the electrolyte nature and PEO process parameters on properties of anodized Ti-15Mo alloy intended for biomedical applications. Metals 2018, 8, 370. [CrossRef]

21. Astashina, N.; Lugovskoy, A.; Kossenko, A.; Lugovskoy, S.; Rogozhnikov, G.; Zinigrad, M. Investigation of the effectiveness of dental implant osseointegration characterized by different surface types. Metals 2017, 7, 203. [CrossRef] 
22. Marques, I.d.S.V.; Alfaro, M.F.; da Cruz, N.C.; Mesquita, M.F.; Sukotjo, C.; Mathew, M.T.; Barão, V.A.R. Tribocorrosion behavior of biofunctional titanium oxide films produced by micro-arc oxidation: Synergism and mechanisms. J. Mech. Behav. Biomed. Mater. 2016, 60, 8-21. [CrossRef]

23. Sukuroglu, E.E.; Farzi, H.; Sukuroglu, S.; Totik, Y.; Arslan, E.; Efeoglu, I. The effect of plasma electrolytic oxidation process parameters on the tribocorrosion properties of $\mathrm{TiO}_{2}$ coatings. J. Adhes. Sci. Technol. 2017, 31, 1361-1373. [CrossRef]

24. Alves, A.C.; Oliveira, F.; Wenger, F.; Ponthiaux, P.; Celis, J.-P.; Rocha, L.A. Tribocorrosion behaviour of anodic treated titanium surfaces intended for dental implants. J. Phys. D Appl. Phys. 2013, 46, 404001-9. [CrossRef]

25. Wu, S.D.; Zhang, H.; Dong, X.D.; Ning, C.Y.; Fok, A.S.L.; Wang, Y. Physicochemical properties and in vitro cytocompatibility of modified titanium surfaces prepared via micro-arc oxidation with different calcium concentrations. Appl. Surf. Sci. 2015, 329, 347-355. [CrossRef]

26. Ishizawa, H.; Ogino, M. Formation and characterization of anodic titanium oxide films containing Ca and P. J. Biomed. Mater. Res. 1995, 29, 65-72. [CrossRef]

27. Abbasi, S.; Golestani-Fard, F.; Mirhosseini, S.M.M.; Ziaee, A.; Mehrjoo, M. Effect of electrolyte concentration on microstructure and properties of micro arc oxidized hydroxyapatite/titania nanostructured composite. Mater. Sci. Eng. C 2013, 33, $2555-2561$. [CrossRef]

28. Park, I.S.; Bae, T.S.; Seol, K.W. Surface Characteristics of Anodized and Hydrothermally Treated Titanium with an Increasing Concentration of Calcium Ion. Met. Mater. Int. 2006, 12, 399-406. [CrossRef]

29. Alves, A.C.; Costa, A.I.; Toptan, F.; Alves, J.L.; Leonor, I.; Ribeiro, E.; Reis, R.L.; Pinto, A.M.P.; Fernandes, J.C.S. Effect of bio-functional MAO layers on the electrochemical behaviour of highly porous Ti. Surf. Coat. Technol. 2020, 386, 125487. [CrossRef]

30. Alves, S.A.; Rossi, A.L.; Ribeiro, A.R.; Toptan, F.; Pinto, A.M.; Shokuhfar, T.; Celis, J.P.; Rocha, L.A. Improved tribocorrosion performance of bio-functionalized $\mathrm{TiO}_{2}$ nanotubes under two-cycle sliding actions in artificial saliva. J. Mech. Behav. Biomed. Mater. 2018, 80, 143-154. [CrossRef] [PubMed]

31. Zywitzki, O.; Modes, T.; Sahm, H.; Frach, P.; Goedicke, K.; Glöß, D. Structure and properties of crystalline titanium oxide layers deposited by reactive pulse magnetron sputtering. Surf. Coat. Technol. 2004, 180-181, 538-543. [CrossRef]

32. Sousa, L.; Alves, A.C.; Guedes, A.; Toptan, F. Corrosion and tribocorrosion behaviour of Ti-B4C composites processed by conventional sintering and hot-pressing technique. J. Alloys Compd. 2021, 885, 161109. [CrossRef] 